\title{
Cyclic Adenosine 3':5'-Monophosphate and Cytosolic Calcium Exert Opposing Effects on Biosynthesis of Tetrodotoxin-sensitive Sodium Channels in Rat Muscle Cells ${ }^{1}$
}

\author{
SCOTT J. SHERMAN, JOHN CHRIVIA AND WILLIAM A. CATTERALL ${ }^{2}$
}

Department of Pharmacology, University of Washington, Seattle, Washington 98195

\begin{abstract}
We have previously presented evidence that electrical activity and increased cytosolic calcium reduce the density of sarcolemmal tetrodotoxin (TTX)-sensitive sodium channels in cultured rat muscle cells (Sherman, S. J., and W. A. Catterall (1984) Proc. Natl. Acad. Sci. U. S. A. 81: 262-266). We show here that growth of cells in ryanodine has a biphasic effect on sodium channel number. At low concentrations $(0.3$ to $10 \mu \mathrm{M}$ ) where this drug releases calcium from the sarcoplasmic reticulum into the cytoplasm, sodium channel number is reduced 62\%; whereas, at higher concentrations where total cellular calcium is depleted, the density of sodium channels is increased $40 \%$ above control. These results provide further evidence for modulation of sodium channel number by cytosolic calcium. Growth of muscle cells in the presence of agents that mimic cyclic AMP (CAMP) action or increase intracellular cAMP levels including 8-bromo-cyclic AMP (8-BrcAMP), cyclic nucleotide phosphodiesterase inhibitors, and forskolin increased sodium channel density up to $125 \%$. This action did not involve changes in spontaneous electrical activity. Dibutyryl cGMP had no effect. Measurement of the turnover rate of sodium channels after block of channel accumulation by tunicamycin $(1.5 \mu \mathrm{g} / \mathrm{ml})$ gave a halftime of $18 \mathrm{hr}$ for exponential decay of TTX-sensitive sodium channels in cultured rat muscle cells after an initial 6-hr lag period. Treatments which modulate sodium channel number through changes in cytosolic calcium or CAMP had no effect on the rate of channel turnover. The increase of sodium channel number after inhibition of electrical activity or treatment with 8-BrcAMP was half-maximal at $17 \mathrm{hr}$, consistent with an increase in the rate of sodium channel biosynthesis and/or incorporation into the sarcolemma without a change in channel tumover time. We conclude that cytosolic calcium decreases and CAMP increases sodium channel number by modulating the rate of biosynthesis and/or processing of channel components. The biochemical mechanisms of these regulatory effects are considered.
\end{abstract}

Voltage-sensitive $\mathrm{Na}^{+}$channels are responsible for the rapid depolarization of the plasma membrane during the action potential

Received August 13, 1984; Revised October 22, 1984;

Accepted October 24, 1984

\footnotetext{
1 This research was supported by a research grant from the Muscular Dystrophy Association to W. A. C. and a fellowship from Medical Scientist Training Program Grant GM-07266 to S. J. S.

${ }^{2}$ To whom correspondence should be addressed.
}

in electrically excitable tissues including skeletal muscle. Myocytes obtained from fetal rats or chickens and maintained in dissociated cell culture have voltage-sensitive $\mathrm{Na}^{+}$channels that are similar, if not identical, to those found in adult skeletal muscle in vivo with respect to their electrophysiological behavior (Spector and Prives, 1977), neurotoxin sensitivities, and developmental time course (Catterall, 1980b; Frelin et al., 1981; Sherman et al., 1983). In addition, cultured muscle cells from rat, but not chick, possess a second type of voltage-sensitive $\mathrm{Na}^{+}$channel which is characteristic of fetal mammalian skeletal muscle (Kidokoro et al., 1975). These channels are distinguished by their neurotoxin sensitivities. The tetrodotoxin (TTX)-serısitive adult form of the muscle sodium channel binds the inhibitors $\Pi T X$ and saxitoxin (STX) with high affinity at neurotoxin receptor site 1 and exhibits substantially higher affinity for Leiurus scorpion toxin than for sea anemone toxins at neurotoxin receptor site 3 (Narahashi, 1974; Ritchie and Rogart, 1977; Catterall, 1980a, b; Sherman et al., 1983). The TTX-insensitive sodium channels of fetal or denervated mammalian skeletal muscle have 100-fold lower affinity for $\Pi X$ at neurotoxin receptor site 1 (Redfern and Thesleff, 1971; Pappone, 1980) and bind sea anemone toxin II from Anemonia sulcata with higher affinity than Leiurus scorpion toxin at receptor site 3 (Lawrence and Catterall, 1981).

The surface density of the $\Pi \mathrm{X}$-sensitive sodium channels may be sclectively quantitated by measuring the specific binding of $\left[{ }^{3} \mathrm{H}\right]$ STX (for reviews, see Catterall, 1980a; Ritchie and Rogart, 1977). In nerve and adult skeletal muscle cells, binding sites for $\left[{ }^{3} \mathrm{H}\right] \mathrm{STX}$ represent functional sodium channels. Similarly, in rat skeletal muscle cells developing in vitro, the high-affinity binding sites for $\left[{ }^{3} \mathrm{H}\right] \mathrm{STX}$ correspond to sodium channels having a $K_{1}$ for $\pi X$ at $37^{\circ} \mathrm{C}$ of 10 to $20 \mathrm{~nm}$ as measured in ion flux experiments (Sherman et al., 1983) or in voltage clamp experiments (T. Gonoi, S. J. Sherman, and W. A. Catterall, unpublished results). Using $\left[{ }^{3} \mathrm{H}\right] \mathrm{STX}$ binding as an assay method, we have recently found that the sarcolemmal density of the $\Pi \mathrm{TX}$-sensitive channel in cultured muscle cells is regulated by electrical activity and cytosolic $\mathrm{Ca}^{++}$levels (Sherman and Catterall, 1984). Chronic pharmacological blockade of the spontaneous electrical activity that is present in cultures of these cells led to a nearly 2-fold increase in the sarcolemmal density of STX receptors. This effect is probably mediated by the concomitant decline of cytosolic $\mathrm{Ca}^{++}$ levels, since increasing cytosolic $\mathrm{Ca}^{++}$with the ionophore $\mathrm{A} 23187$ reduced STX receptor density. These results may reflect the presence of a homeostatic regulatory system controlling electrical excitability in which cytosolic $\mathrm{Ca}^{++}$acts as a negative feedback signal to modulate the surface density of TTX-sensitive channels. In this report, we provide further evidence that cytosolic $\mathrm{Ca}^{++}$regulates the density of $\Pi \mathrm{TX}$-sensitive $\mathrm{Na}^{+}$channels, present experiments showing that the TTX-sensitive $\mathrm{Na}^{+}$channel is also regulated by the intracellular level of cAMP, and examine the mechanism by which these agents modulate sodium channel levels in cultured rat muscle cells. 


\section{Experimental Procedures}

Materials. Chemicals and components of the growth medium were purchased from the following sources: Dulbecco's modified Eagle's medium, from Grand Island Biological Co.; horse and newborn calf serum, from Kansas City Biological Co.; calf-skin collagen, forskolin, tetrodotoxin, and A23187, from Calbiochem; and ryanodine from Penick Chemical Co. Other chemicals were from Sigma.

Saxitoxin was obtained from the Toxicology Study Section, NIH. It was labeled by exchange with ${ }^{3} \mathrm{H}_{2} \mathrm{O}$ (Ritchie et al., 1976), purified, and characterized by a modification (Waechter et al., 1983) of previously described methods (Catterall et al., 1979; Rhoden and Goldin, 1979). The radiochemical purity of the several batches used ranged from 75 to $85 \%$ and the specific radioactivity ranged from 7.4 to $12.2 \mathrm{Ci} / \mathrm{mMol}$. Tunicamycin was obtained from Dr. John Douros, Natural Products Branch, Developmental Therapeutics Program, Division of Cancer Treatment, NCl, NIH. Bupivacaine was obtained from Dr. Bertil Takman, Astra Pharmaceuticals, Sweden. R24571 was obtained from Laboratory of Biochemistry, Janssen Pharmaceutica Research Laboratories, B-2340 Beerse, Belgium.

Preparation of primary cultured muscle cells. Myocytes were obtained from the forelimbs of 20-d Sprague-Dawley rat fetuses by enzymatic dissociation as previously described (Lawrence and Catterall, 1981). The myocytes were seeded at a density of $9.0 \times 10^{6}$ cells $/ 150-\mathrm{mm}$ dish and maintained in a growth medium consisting of $85 \%$ Dulbecco's modified Eagle's medium, $10 \%$ horse serum, $5 \%$ newborn calf serum, $10 \mu \mathrm{g} / \mathrm{ml}$ streptomycin, and 30 $\mu \mathrm{g} / \mathrm{ml}$ penicillin $\mathrm{G}$. The sera were heat inactivated by incubation at $56^{\circ} \mathrm{C}$ for 30 min. After $4 \mathrm{~d}$ in culture, when myocyte fusion to form multinucleate myotubes was complete, the growth medium was replaced $(30 \mathrm{ml} /$ dish) and supplemented with $10 \mu \mathrm{M}$ cytosine arabinoside to inhibit fibroblast proliferation and experimental agents as described for each experiment. These agents were added from a 100-fold concentrated stock solution sterilized by micropore filtration (0.22- $\mu \mathrm{m}$ nitrocellulose filters; Millipore Corp.) or from a 1000 -fold concentrated ethanolic stock solution. In control experiments, we found $0.1 \%$ ethanol had no effect on the cell morphology or development of TTX-sensitive $\mathrm{Na}^{+}$channels.

At the end of the period of growth in the presence of experimental agents, the cells were washed twice with a choline-substituted wash medium con sisting of $163 \mathrm{~mm}$ choline chloride, $5 \mathrm{~mm}$ Hepes (adjusted to $\mathrm{pH} 7.4$ with Tris base), $1.8 \mathrm{mM} \mathrm{CaCl}_{2}$, and $0.8 \mathrm{mM} \mathrm{MgSO}_{4}$. The cells were then removed from the plate with a tefion-coated spatula in the presence of $3 \mathrm{ml}$ of $135 \mathrm{~mm}$ choline chloride, $50 \mathrm{~mm}$ potassium phosphate $(\mathrm{pH} 7.4), 1.8 \mathrm{mM} \mathrm{CaCl}_{2}$, and $0.8 \mathrm{mM} \mathrm{MgSO}_{4}$. The cells were centrifuged at $3000 \times \mathrm{g}$ for $5 \mathrm{~min}$, and the supernatant was discarded. The cells were homogenized in $0.7 \mathrm{ml}$ of the potassium phosphate-buffered medium with a Tek-Mar Tissuemizer at the half-maximal setting for $5 \mathrm{sec}$. The samples were then stored in liquid $\mathrm{N}_{2}$ until assayed.

$\left[^{3} H\right] S T X$ binding assay. The specific binding of $\left[{ }^{3} H\right] S T X$ was measured at $0^{\circ} \mathrm{C}$ by the rapid vacuum filtration assay described previously (Sherman et al., 1983). Unless stated otherwise, the total binding capacity was determined by incubation with $15 \mathrm{nM}\left[{ }^{3} \mathrm{H}\right] \mathrm{STX}$, and nonspccific binding was measured by incubation with $15 \mathrm{nM}\left[{ }^{3} \mathrm{H}\right] \mathrm{STX}$ in the presence of $2 \mu \mathrm{M}$ TTX. Protein was determined by the method of Lowry et al. (1951) with bovine albumin as the standard. Sarnples were diluted to the appropriate rarige of protein content in a solution of $0.2 \%$ sodium dodecyl sulfate in $0.4 \mathrm{M} \mathrm{NaOH}$

\section{Results}

Mononucleated myocytes were obtained by trypsinization of skeletal muscle from fetal rats one day before birth. After seeding into tissue culture dishes, these cells undergo several mitoses and then fuse to form postmitotic multinucleated myotubes. The fusion process was complete after 4 days in culture. TTX-sensitive $\mathrm{Na}^{+}$channels begin to appear after $24 \mathrm{hr}$ in culture and continue to develop in a linear time course until the peak density occurs between d 8 and 12 (Sherman et al., 1983). When muscle cells are grown in the presence of the $\mathrm{Ca}^{++}$-specific ionophore A23187 from of 4 to 10 , there is a marked reduction in the development of TTX-sensitive $\mathrm{Na}^{+}$channels (Sherman and Catterall, 1984). The ionophore A23187 increases the permeability to $\mathrm{Ca}^{++}$of the plasma membrane as well as the internal cellular membranes. Thus, in the presence of $\mathrm{A} 23187, \mathrm{Ca}^{++}$moves into the cytosol from both the sarcoplasmic reticulum and the extracellular medium (Hainaut and Desmedt, 1979). At higher concentrations of A23187 (greater than $3 \mu \mathrm{M}$ ) the increased permeability of the plasma membrane overcomes the ability of the cell to extrude cytosolic $\mathrm{Ca}^{++}$, and toxicity becomes evident (Sherman and Catterall, 1984).

In order to provide independent evidence for regulation of sodium channel levels by cytosolic $\mathrm{Ca}^{++}$, we have maintained cells in the presence of ryanodine, an alkaloid which causes the release of $\mathrm{Ca}^{++}$ from the sarcoplasmic reticulum without a generalized ionophoric action (Fairhurst and Hasselbach, 1970). Figure 1 shows the effects of maintaining muscle cells in the presence of increasing concentrations of ryanodine from d 4 to 10 in culture. For ryanodine concentrations between 0.3 and $10 \mu \mathrm{M}$, the density of sodium channels is reduced. At $1 \mu \mathrm{M}$, which is effective in inducing the release of $\mathrm{Ca}^{++}$ from isolated sarcoplasmic reticulum (Jenden and Fairhurst, 1969), the maximum reduction in TTX-sensitive channel density occurs. The $62 \%$ decrease observed under these conditions is comparable to the previously reported effect of $1 \mu \mathrm{M}$ A23187 (Sherman and Catterall, 1984). As the concentration of ryanodine is increased further, the density of TTX-sensitive channels begins to return toward control values and eventually exceeds ( $p<0.05$; Students $t$ test) control levels by $40 \%$. These higher concentrations of ryanodine cause $\mathrm{Ca}^{++}$efflux from muscle cells (Bianchi, 1963; Hadju, 1969) and deplete the intracellular $\mathrm{Ca}^{++}$stores (Pezzementi and Schmidt, 1981). Under these conditions, cytosolic $\mathrm{Ca}^{++}$returns to low leveis. The time-averaged concentration may be reduced beyond the levels in control cells, since there is a reduced pool of $\mathrm{Ca}^{++}$that may be released from the sarcoplasmic reticulum in response to the spontaneous electrical activity. Thus, the biphasic dose response of the density of TTX-sensitive channels to ryanodine parallels the expected effects of ryanodine on cytosolic $\mathrm{Ca}^{++}$. This result constitutes further evidence that in skeletal muscle cells, the number of sodium channels may be regulated by the level of cytosolic $\mathrm{Ca}^{++}$

The regulation of many processes by cytosolic $\mathrm{Ca}^{++}$is mediated by the $\mathrm{Ca}^{++}$-binding protein calmodulin (Cheung, 1980; Klee et al., 1980). In order to investigate whether calmodulin mediates the action of cytosolic $\mathrm{Ca}^{++}$to regulate the number of $T T X$-sensitive $\mathrm{Na}^{+}$ channels, we maintained cells from d 4 to 10 in the presence of the anticalmodulin drugs trifluoperazine (Levin and Weiss, 1977; Weiss and Levin, 1978) and R2457 1 (Van Belle, 1981; Gietzen et al., 1981). For both of these drugs, we tested a single concentration which was found in initial experiments to be the highest concentration that did not cause visible signs of cell toxicity. These concentrations

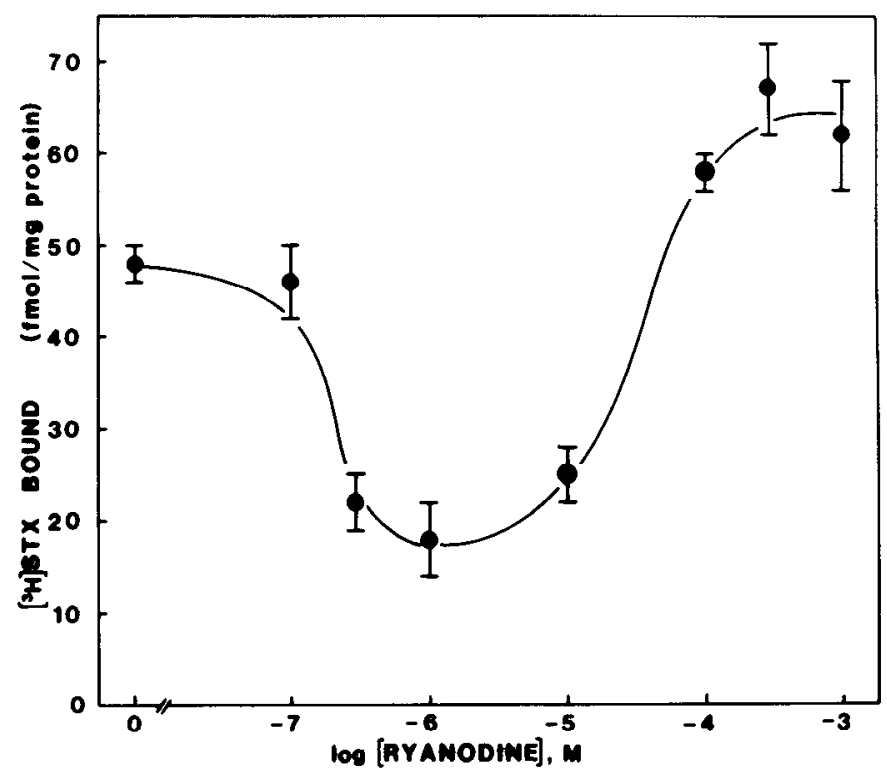

Figure 1. Effect of ryanodine on the density of $T T X$-sensitive $\mathrm{Na}^{+}$channels. Muscle cells were maintained in the presence of the indicated concentrations of ryanodine for $5 \mathrm{~d}$ and the density of TTX-sensitive channels was quantitated by measuring the specific binding of $\left[{ }^{3} \mathrm{H}\right] \mathrm{STX}$ as described under "Experimental Procedures." 
correspond quite closely to the $K_{1}$ for inhibition of calmodulinactivated enzymes such as phosphodiesterase and $\mathrm{Ca}^{++}, \cdot \mathrm{Mg}^{++}$ activated adenosine triphosphatase (Levin and Weiss, 1977; Van Belle, 1981; Gietzen et al., 1981). Both drugs caused a 55\% increase in the density of TTX-sensitive $\mathrm{Na}^{+}$channels (Table I), which is approximately half of the effect observed when the action potential dependent release of $\mathrm{Ca}^{++}$is blocked by bupivacaine. This result is conșistent with the hypothesis that the regulatory action of cytosolic $\mathrm{Ca}^{++}$is mediated by interaction with calmodulin. However, since the toxicity of the anticalmodulin drugs prevented determination of full dose-response curves in these long-term experiments, our results are not conclusive, and experiments using a different approach are necessary.

Regulatory effects of cyclic nucleotides. The role of cyclic nucleotides in regulating the density of TTX-sensitive $\mathrm{Na}^{+}$channels was investigated by maintaining cultured muscle cells for $5 \mathrm{~d}$ in the preserice of agents which are known to increase the intracellular level of CAMP or CGMP or to mimic their effects. Table II shows that the membrane-permeable CAMP analogue 8-BrcAMP produced a $67 \%$ increase in the density of TTX-sensitive $\mathrm{Na}^{+}$channels. On the other hand, the cGMP derivative dibutyryl-cGMP had no effect. The alkaloid forskolin, which directly stimulates the catalytic subunit of adenylate cyclase (Seamon and Daly, 1981), was also effective in increasing the density of TTX-sensitive $\mathrm{Na}^{+}$channels as much as $106 \%$ above control levels. Although a full dose-response curve was not constructed for forskolin, several concentrations were tested, and the results shown in Table II indicate a half-maximal cffect at 30 $\mu \mathrm{M}$ consistent with its potency in other systems (Seamon and Daly, 1981). Indirectly increasing the level of CAMP by inhibiting its hy-

TABLE I

Effect of anti-calmodulin agents on the density of $\pi X$-sensitive $\mathrm{Na}^{+}$ channels

Muscle cells were maintained for $5 d$ in the presence or absence of anticalmoduliri drugs. The density of TTX-sensitive $\mathrm{Na}^{+}$channels was then quantitated by measuring the specific binding of $\left[{ }^{3} \mathrm{H}\right] \mathrm{STX}$ as described under "Experimental Procedures." Each value is the mean of three determinations.

\begin{tabular}{lc}
\hline & $\begin{array}{c}{\left[{ }^{3} \mathrm{H}\right] \mathrm{STX} \text { Bound }} \\
\text { (fmol/mg of protein) }\end{array}$ \\
\hline Control & $77 \pm 5$ \\
$3 \mu \mathrm{M}$ R24571 & $119 \pm 12$ \\
$30 \mu \mathrm{M}$ Trifluoperazine & $119 \pm 8$ \\
\hline
\end{tabular}

TABLE ॥

Effect of agents which increase CAMP on the density of $T \mathrm{TX}$-sensitive $\mathrm{Na}^{+}$ channels

Muscle cells were grown for $5 \mathrm{~d}$ in the presence of the indicated agents. The density of TTX-sensitive $\mathrm{Na}^{+}$channels was then determined by measuring the specific binding of $\left[{ }^{3} \mathrm{H}\right] \mathrm{STX}$ as described under "Experimental Procedures."

\begin{tabular}{lcc}
\hline & $\begin{array}{c}{\left[{ }^{3} \mathrm{H}\right] \mathrm{ST} \times \text { Bound }} \\
\text { (fmol/mg of protein) }\end{array}$ & Percentage Increase \\
\hline Experiment 1 & & \\
Control & $68 \pm 3$ & 67 \\
$1 \mathrm{mM}$ 8-BrcAMP & $113 \pm 467$ & 0 \\
$1 \mathrm{~mm}$ Dibutyryl- & $68 \pm 1$ & \\
CGMP & & 57 \\
$1 \mathrm{mM}$ Theophylline & $107 \pm 4$ & 31 \\
$10 \mu \mathrm{M}$ Forskolin & $89 \pm 4$ & 59 \\
$30 \mu$ Forskolin & $108 \pm 4$ & 106 \\
$50 \mu \mathrm{M}$ Forskolin & $140 \pm 6$ & 106 \\
$100 \mu \mathrm{M}$ Forskolin & $140 \pm 5$ & \\
Experiment 2 & & \\
Control & $53 \pm 8$ & 96 \\
$1 \mathrm{mM}$ 8-BrcAMP & $104 \pm 2$ & 187 \\
$1 \mathrm{mM}$ 8-BrcAMP + & $152 \pm 4$ & \\
$40 \mu \mathrm{M}$ bupivacaine & & \\
\hline
\end{tabular}

drolysis by cyclic nucleotide phosphodiesterase was also effective in increasing channel density. Theophylline $(1 \mathrm{~mm}$ ) caused a $57 \%$ increase in channel number (Table II). Figure 2 shows the dose response of the density of STX receptors to maintenance for $5 \mathrm{~d}$ in increasing concentrations of caffeine and 3-methyl-4-isobutyl-xanthine. These agents produce significant increases in the density of TTX-sensitive channels with $K_{0.5}$ values (300 and $100 \mu \mathrm{M}$, respectively) that correspond closely with their ability to inhibit phosphodiesterase (Appleman et al., 1973). These results show that several mechanistically independent methods of increasing cAMP levels produce a nearly 2 -fold increase in the density of TTX-sensitive $\mathrm{Na}^{+}$ channels.

It is possible that increased levels of cAMP do not regulate the density of TTX-sensitive channels directly but instead may modify the degree of spontaneous electrical activity present and thus have an indirect effect. Visual inspection of the cultures did not reveal an effect of cyclic nucleotides on spontaneous contraction. In order to test this possibility more directly, muscle cells were maintained for 5 $\mathrm{d}$ in the presence of both bupivacaine and 8-BrcAMP. The density of TTX-sensitive $\mathrm{Na}^{+}$channels was then compared with cells maintained in each of these agents alone. Bupivacaine $(40 \mu \mathrm{M})$ completely blocks spontaneous contractile activity (Sherman and Cattcrall, 1984). Even under these conditions, 8-BrcAMP produced an additive increase in the density of TTX-sensitive channels indicating that the level of CAMP has a regulatory effect apart from any indirect influence on spontaneous electrical activity.

Turnover rate of $\Pi X$-sensitive sodium channels. The protein components of the TTX-sensitive $\mathrm{Na}^{+}$channels of rat brain and skeletal muscle have recently been isolated. These studies have provided strong evidence that the TTX-sensitive channel is a membrane glycoprotein (Hartshorne and Catterall, 1981; Cohen and Barchi, 1981). In mouse neuroblastoma and chick skeletal muscle cells, protein glycosylation is required for the maintenance of functional TTX-sensitive channels, since the number of functional channels is reduced in cells grown in the presence of tunicamycin (BarSagi et al., 1983; Waechter et al., 1983), a specific inhibitor of $N$ linked protein glycosylation (for reviews, see Struck and Lennarz, 1980 and Elbein, 1981). Tunicamycin presumably interferes with the incorporation or maintenance in the plasma membrane of newly synthesized channel polypeptides; however, the alternate possibility that unglycosylated channels do not bind the neurotoxin probes

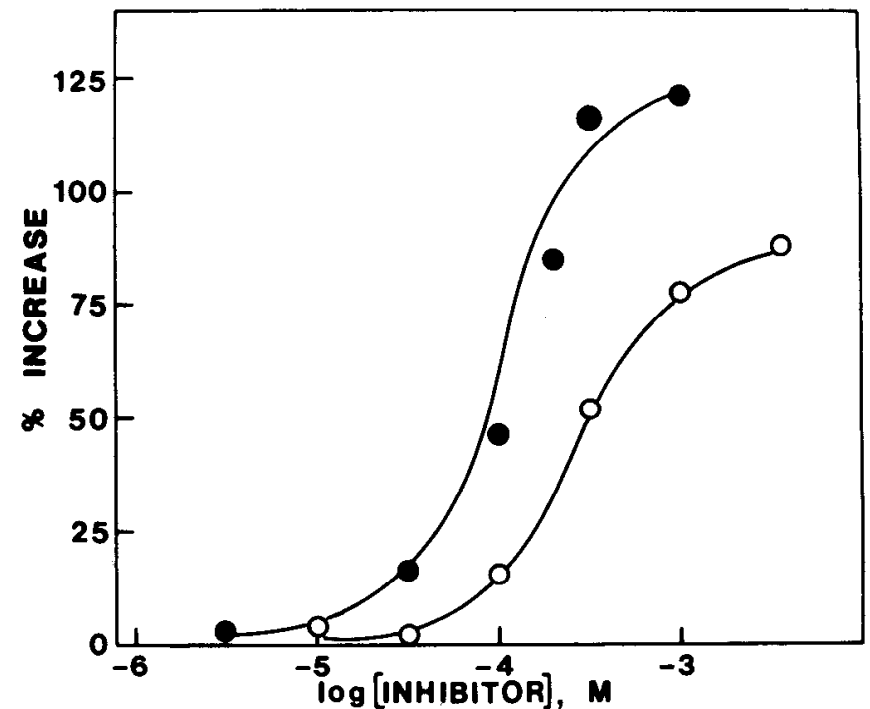

Figure 2. Effect of phosphodiesterase inhibitors on the density of $\Pi \mathrm{TX}$ sensitive $\mathrm{Na}^{+}$channels. Muscle cells were maintained in the indicated concentrations of caffeine $(O)$ or 3-isobutyryl-4-methylxanthine $(O)$ for $5 \mathrm{~d}$ and the density of TTX-sensitive channels was quantitated by measuring the specific binding of [ $\left.{ }^{3} \mathrm{H}\right] \mathrm{STX}$ as described under "Experimental Procedures." 
used for detection has not been excluded. In either case, the turnover rate of the TTX-sensitive channel may be determined from the kinetics of the decline of STX receptor density in cells exposed to tunicamycin.

Previous experiments have indicated that rat muscle cells have a single class of high-affinity binding sites for $\left[{ }^{3} \mathrm{H}\right] \mathrm{STX}$ (Sherman et al., 1983; Sherman and Catterall, 1984). Binding of $\left[{ }^{3} \mathrm{H}\right] \mathrm{STX}$ is described by a linear Scatchard plot with a $B_{\max }$ in the range of 80 to $120 \mathrm{fmol} /$ $\mathrm{mg}$ protein. Figure 3 illustrates the effect of growth of rat muscle cells in the presence of $1 \mu \mathrm{g} / \mathrm{ml}$ tunicamycin on the number of highaffinity $\left[{ }^{3} \mathrm{H}\right] \mathrm{STX}$ binding sites. $B_{\text {max }}$ is reduced from 83 to $40 \mathrm{fmol} /$ $\mathrm{mg}$. No new STX receptors of lower affinity appear in cells grown in the presence of tunicamycin. Thus, growth in tunicamycin sharply reduces the number of functional sodium channels in rat muscle cells as previously observed in neuroblastoma cells and chick muscle cells (Waechter et al., 1983; Bar-Sagi et al., 1983), confirming that the tunicamycin can be used to determine channel turnover rate.

The turnover rate of TTX-sensitive $\mathrm{Na}^{+}$channels in cultured muscle cells was determined with this approach in the presence of agents that modulate channel number. After a 6 -hr lag period, the channel density in control cells decreased with first-order kinetics to $39 \%$ of the initial value at $30 \mathrm{hr}$ (Fig. 4). The half-life of the TTX-sensitive channel derived from these data is $18 \mathrm{hr}$ which is comparable to the values obtained in earlier studies of TTX-sensitive channels in mouse neuroblastoma cells (Waechter et al., 1983) and cultured chick muscle cells (Bar-Sagi et al., 1983). In order to determine whether electrical activity and cytosolic $\mathrm{Ca}^{++}$influence the turnover rate of the TTX-sensitive $\mathrm{Na}^{+}$channel, muscle cells were maintained in the presence of bupivacainc or A23187 for $4 \mathrm{~d}$ and then exposed to $1.5 \mu \mathrm{g} / \mathrm{ml}$ tunicamycin plus bupivacaine or A23187. Muscle cells that were maintained in the presence of bupivacaine had a 2- to 4fold higher density of TTX-sensitive channels but exhibited an identical fractional decline when exposed to tunicamycin (Fig. 4). Similarly, growth of cells in the presence of A23187 produced a $46 \%$ decrease in channel density without increasing the turnover rate (Fig. 4).

We have also examined the effect of bupivacaine on sodium

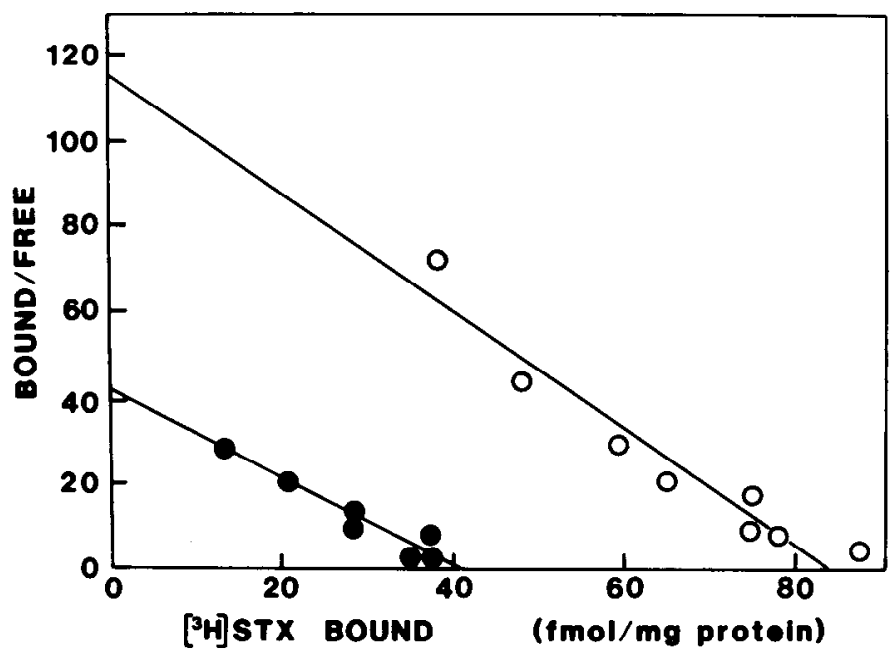

Figure 3. Scatchard analysis of $\left[{ }^{3} \mathrm{H}\right] \mathrm{STX}$ binding to muscle cells exposed to tunicamycin. Muscle cells were maintained in culture for $8 \mathrm{~d}$ as described under "Experimental Procedures." At that time the medium was renewed with $(\Theta)$ or without $(O)$ the addition of $1.5 \mu \mathrm{g} / \mathrm{ml}$ of tunicamycin. After $30 \mathrm{hr}$ the cells were harvested and the specific binding of $\left[{ }^{3} \mathrm{H}\right] \mathrm{STX}$ was measured at several channels concentrations ranging from $1.0 \mathrm{~nm}$ to $25 \mathrm{nM}$ as described under "Experimental Procedures." The results have been plotted according to the method of Scatchard. The units on the ordinate are fmol-mg protein ${ }^{-1}$ $\mathrm{nM}^{-1}$. The binding parameters derived from a least squares analysis are as follows: control cells, $B_{\max }=83.2 \mathrm{fmol} / \mathrm{mg}$ of protein, $K_{D}=0.98 \mathrm{~nm}$; tunicamycin-treated cells, $B_{\max }=41.6 \mathrm{fmol} / \mathrm{mg}$ protein, $K_{\mathrm{D}}=1.0 \mathrm{nM}$.

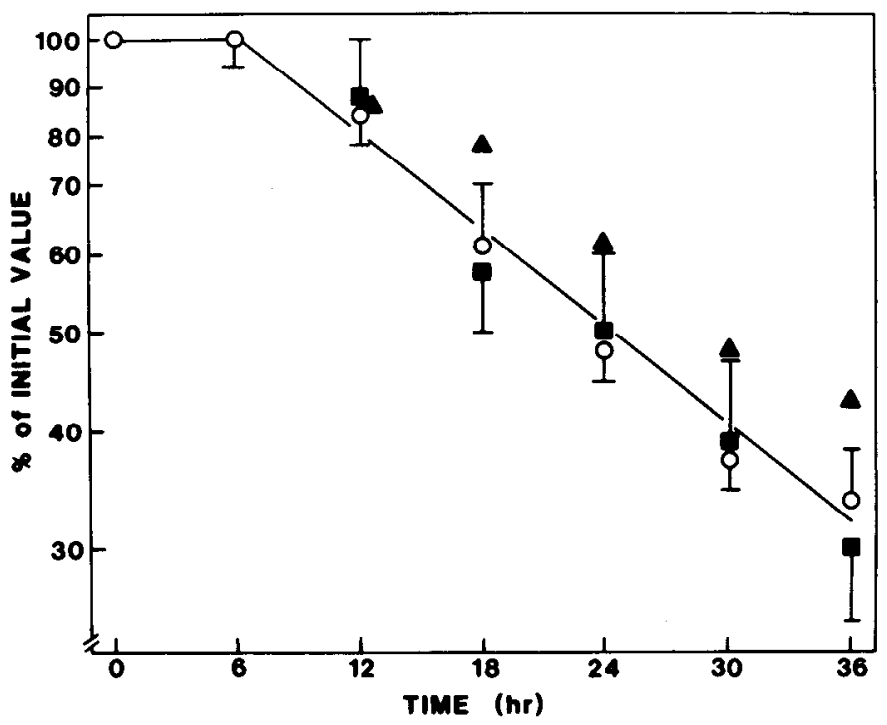

Figure 4. Effect of tunicamycin on the density of $\mathrm{TX}$-sensitive $\mathrm{Na}^{+}$ channels in cultured muscle cells. Muscle cells were maintained for $4 \mathrm{~d}$ in the presence of growth medium supplemented with $40 \mu \mathrm{M}$ bupivacaine ( $\square$ ), $1 \mu \mathrm{M} \mathrm{A23187}(\mathbf{A})$, or no additions (O). The medium was then replaced with fresh medium containing the same experimental agents plus $1.5 \mu \mathrm{g} / \mathrm{ml}$ of tunicamycin. The cells were harvested at the indicated time intervals and the density of TTX-sensitive channels was quantitated by measuring the specific binding of $\left[{ }^{3} \mathrm{H}\right] \mathrm{STX}$ as described under "Experimental Procedures." Note that the ordinate is a logarithmic scale. Error bars represent standard error of three separate experiments.

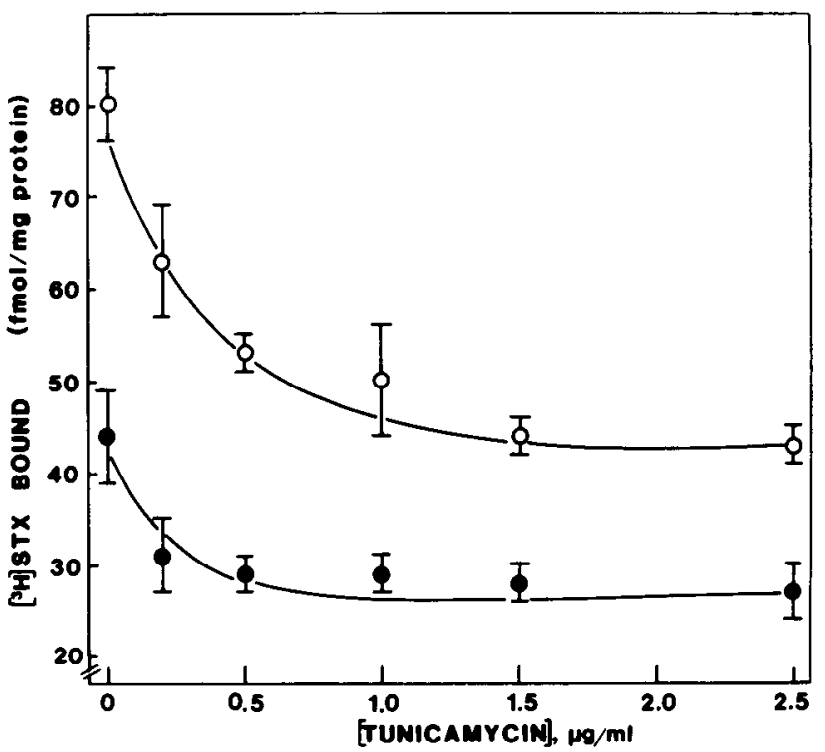

Figure 5. Dose response of the effects of tunicamycin on the density of TTX-sensitive $\mathrm{Na}^{+}$channels. Muscle cells were grown in the presence (O) or absence $(\mathrm{O})$ of $40 \mu \mathrm{M}$ bupivacaine for $4 \mathrm{~d}$. The medium was then renewed with the addition of the indicated concentrations of tunicamycin with or without bupivacaine. After $30 \mathrm{hr}$ maintenance in the presence of tunicamycin the cells were harvested and the density of $\Pi \mathrm{X}$-sensitive $\mathrm{Na}^{+}$channels was determined by the specific binding of $\left.{ }^{3} H\right]$ STX as described in "Experimental Procedures."

channel turnover at a fixed time $(30 \mathrm{hr})$ and varying concentrations of tunicamycin. The results (Fig. 5) show that tunicamycin is approximately equally effective in reducing sodium channel number in cells grown under control conditions or in the presence of bupivacaine. In each case, growth for $30 \mathrm{hr}$ in tunicamycin at 1.5 to $2.5 \mu \mathrm{g} / \mathrm{ml}$ reduced sodium channel number by $45 \%$ consistent with the results of Figure 3. Taken together, the results of Figures 4 and 5 show that 
both the increased channel density produced by blockade of spontaneous electrical activity and the decrease in channel density due to growth in A23187 are not due to alterations in the rate of sodium channel turnover but rather must reflect an increased rate of synthesis or posttranslational processing.

Since the tunicamycin-induced decline of TTX-sensitive $\mathrm{Na}^{+}$channels follows first-order kinetics, the effect of various pharmacological agents on the channel turnover rate may be quantitated by measurement of channel density before and after a 30-hr exposure to tunicamycin. Table III shows the results of an experiment in which this method was used to assess the channel half-life in muscle cells that wore maintaincd for $4 \mathrm{~d}$ in the presence of a varicty of agents which affect levels of cAMP or cytosolic $\mathrm{Ca}^{++}$. These data indicate that increased levels of cAMP produced by 8-BrcAMP, forskolin, or caffeine cause increased channel number without a significant effect on the turnover rate. Similarly, increased levels of cytosolic $\mathrm{Ca}^{++}$ produced by ryanodine and blockade of the calmodulin-dependent effects of cytosolic $\mathrm{Ca}^{++}$with R24571 alter sodium channel number without an influence on channel turnover. These results suggest that regulation of TTX-sensitive $\mathrm{Na}^{+}$channels by electrical activity, cytosolic $\mathrm{Ca}^{++}$, and CAMP must be mediated by alterations in the rate of sodium channel synthesis or processing.

If exposure of muscle cells to bupivacaine or agents which increase cAMP has a rapid regulatory action to increase the rate of channel synthesis with no effect on channel half-life, then the approach to the higher steady-state level should have a $t_{1 / 2}$ equivalent to the turnover time of the TTX-sensitive $\mathrm{Na}^{+}$channel according to the equation $A=A_{\max }\left(1-e^{-k t}\right)$, where $A$ equals the increase in channel density as a function of time $(t)$ and $A_{\max }$ represents the final equilibrium value at the new steady state. In this formulation the constant $k=\ln 2 / t_{1 / 2}$ and is equivalent to the rate constant for channel turnover. Figure 6 shows the time course of the effect of bupivacaine and 8-BrcAMP. The half-maximal effect of both of these agents occurs at $17 \mathrm{hr}$ in good agreement with $t_{1 / 2}$ of the channel determined earlier (see Fig. 3). This result is consistent with a relatively rapid onset of alteration in the rate of channel synthesis and/or processing while the turnover rate remains constant.

\section{Discussion}

Regulation of sodium channel number by cytosolic $\mathrm{Ca}^{++}$. In this report, we provide further evidence for the regulation of the number of TTX-sensitive sodium channels by electrical activity and cytosolic $\mathrm{Ca}^{++}$. Ryanodine has a biphasic effect on intracellular $\mathrm{Ca}^{++}$concentration (Hainaut and Desmedt, 1979; Fairhurst and Hasselbach, 1970; Jenden and Fairhurst, 1969). The effect of ryanodine on sodium channel number parallels its effects on cytosolic $\mathrm{Ca}^{++}$; low concentrations of ryanodine increase cytosolic $\mathrm{Ca}^{++}$and reduce

TABLE III

Effects of experimental agents which alter cytosolic $\mathrm{Ca}^{++}$or CAMP levels on the turnover rate of the $\Pi X$-sensitive $\mathrm{Na}^{+}$channel

Muscle cells were maintained in the presence of the indicated agents for $4 \mathrm{~d}$. The cells were then divided into two groups. In one group the growth medium was renewed with medium containing the experimental agents indicated plus $1.5 \mu \mathrm{g} / \mathrm{ml}$ of tunicamycin. The other group received new growth medium containing the indicated agents without tunicamycin. After $30 \mathrm{hr}$ the cells were harvested and the density of TTX-sensitive $\mathrm{Na}^{+}$channels was determined as described under "Experimental Procedures."

\begin{tabular}{lrcc}
\hline \multirow{2}{*}{ Growth Conditions } & \multicolumn{3}{c}{$\begin{array}{c}\text { STX Bound } \\
\text { (fmol/mg of protein) }\end{array}$} \\
\cline { 2 - 4 } & -Tunicamycin & +Tunicamycin & Ratio \\
\hline Control & $90 \pm 6$ & $46 \pm 4$ & $0.51 \pm 0.05$ \\
Caffeine $(3 \mathrm{mM})$ & $162 \pm 6$ & $78 \pm 4$ & $0.48 \pm 0.03$ \\
Ryanodine $(3 \mu \mathrm{M})$ & $47 \pm 4$ & $21 \pm 1$ & $0.45 \pm 0.04$ \\
Forskolin $(50 \mu \mathrm{M})$ & $140 \pm 5$ & $78 \pm 2$ & $0.56 \pm 0.05$ \\
R24571 $(3 \mu \mathrm{M})$ & $135 \pm 5$ & $80 \pm 9$ & $0.59 \pm 0.06$ \\
8-BrCAMP $(1 \mathrm{IIM})$ & $151 \pm 5$ & $65 \pm 3$ & $0.43 \pm 0.03$ \\
\hline
\end{tabular}

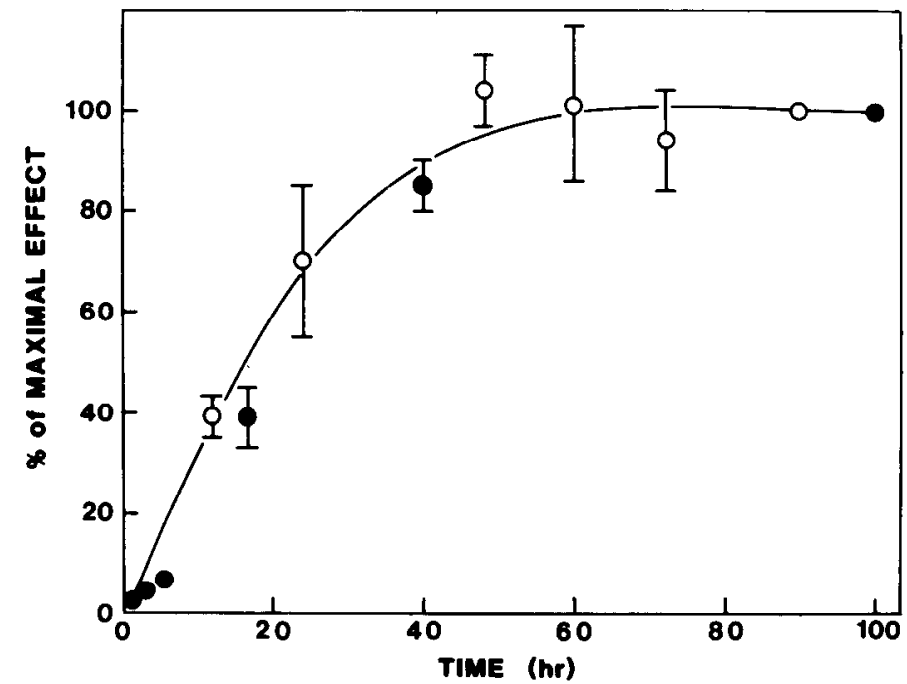

Figure 6. Time course of the effects of bupivacaine and 8-BrcAMP. Muscle cells were maintained under standard growth conditions for $8 \mathrm{~d}$. The medium was renewed and supplemented with $1 \mathrm{~mm} 8-\operatorname{BrcAMP}(\square), 40 \mu \mathrm{m}$ bupivacaine $(\Delta)$ or no additions $(\mathbf{C})$. The cells were then harvested at the indicated times and the density of TTX-sensitive $\mathrm{Na}^{+}$channels was quantitated by measuring the specific binding of $\left[{ }^{3} \mathrm{H}\right] \mathrm{STX}$ as described under "Experimental Procedures." For purposes of comparison, the data have been presented as the percentage of maximal response. The maximal increase in binding site density for cells grown in the presence of bupivacaine or 8-BrcAMP was 2.1fold and 1.6-fold, respectively. Error bars represent standard error of three or four replicate samples in a single representative experiment.

sodium channel number, while high concentrations of ryanodine deplete cellular $\mathrm{Ca}^{++}$and increase the number of sodium channels. These results support our previous proposal (Sherman and Catterall, 1984) that $\mathrm{Ca}^{++}$is an intracellular mediator of the effect of electrical activity on channel number.

Calmodulin is the intracellular receptor for $\mathrm{Ca}^{++}$in many of its regulatory actions. Interactions of $\mathrm{Ca}^{++}$with calmodulin are blocked by phenothiazines and other hydrophobic drugs including trifluoperazine and R'24571 (Levin and Weiss, 1977; Weiss and Levin, 1978; Van Belle, 1981; Gietzen et al., 1981). However, these drugs are not highly specific. Growth of rat skeletal muscle cells in the presence of these agents increases sodium channel number as expected if a $\mathrm{Ca}^{++}$-calmodulin complex is required to mediate the action of $\mathrm{Ca}^{++}$. These results provide preliminary evidence that a $\mathrm{Ca}^{++}$-calmodulin complex is an intracellular regulator of sodium channel number in response to changes in the level of electrical activity.

Membrane glycoproteins like the sodium channel undergo a complex series of biochemical modifications as they move from synthesis as a precursor polypeptide in the rough endoplasmic reticulum through processing in the Golgi, insertion in the plasma membrane, and internalization and degradation in the lysosomes. Regulation of the number of sodium channels could occur at any one of those steps. In this report, we have shown that the rate of internalizalion and degradalion of the sodium channel after inhibition of the biosynthesis of functional sodium channels with tunicamycin is unchanged by block of electrical activity with bupivacaine or increase of cytosolic $\mathrm{Ca}^{++}$with A23187. These results rule out major effects on channel degradation as the point of regulation of sodium channel levels and implicate one or more of the steps in sodium channel biosynthesis, processing, and insertion in the plasma membrane as the site of regulatory action. Regulation of mRNA levels and/or rates of mRNA translation have been widely recognized as points of regulation of biosynthesis of many proteins. In addition, recent studies have shown that the assembly of the subunits of the nicotinic acetylcholine receptor is a critical point of regulation of biosynthesis of functional oligomeric receptor molecules in a clonal rat muscle cell line (Olson et al., 1984). Further experiments in which 
the individual steps in biosynthesis and processing of the sodium channel subunits and their assembly into a functional complex are measured individually will be necessary to define the site of regulation of sodium channel biosynthesis by electrical activity and $\mathrm{Ca}^{++}$ more precisely.

Regulation of sodium channel number by CAMP. We have found that nonhydrolyzable derivatives which mimic CAMP action (8BrcAMP, dibutyryl CAMP), drugs which block CAMP hydrolysis by phosphodiesterases (theophylline, isobutyl methyl xanthine, cafteine), and agents which stimulate CAMP synthesis (forskolin) all increase the number of TTX-sensitive sodium channels in cultured rat muscle cells. These results provide clear evidence that intracellular CAMP concentration regulates the levels of functional TTXsensitive sodium channels as does intracellular calcium concentration. Treatments which substantially alter the number of sodium channels have no effect on the rate of channel turnover, implying that one of the steps in channel biosynthesis is affected by cAMP as well as $\mathrm{Ca}^{++}$. It will be of interest to determine whether the point of regulation by these two different regulatory pathways is the same.

No mechanism other than activation of protein kinase has been shown to mediate the regulatory effects of CAMP in eukaryotes (Krebs and Beavo, 1979). Thus, the effect of cAMP on the TTXsensitive $\mathrm{Na}^{+}$channel is very likely to be mediated by protein phosphorylation. The $\alpha$-subunit of the TTX-sensitive $\mathrm{Na}^{+}$channel in ral brain is phosphorylated in vitro and in situ by the CAMPdependent protein kinase (Costa and Catterall, 1984). Therefore, it is possible that the processing or assembly of channel subunits is increased by CAMP-dependent phosphorylation resulting in increased overall biosynthesis of functional sodium channels. Alternatively, CAMP-dependent phosphorylation of proteins involved in regulation of gene expression or in biosynthesis or processing of the sodium channel protein may be the basis of the observed regulatory effects.

Interactions between the CAMP-dependent and $\mathrm{Ca}^{++}$-dependent regulatory pathways. There are several similarities between the regulation of channel density by electrical activity/cytosolic $\mathrm{Ca}^{++}$ and CAMP. In both cases, channel density is modulated over a 3- to 4-fold range, the effect is complete in approximately $60 \mathrm{hr}$, and channel synthesis rather than degradation is altered. These similarities may reflect modulation of channel density by two separate and independent regulatory cascades with a common final step or may be due to the extensive interactions between the CAMP-dependent and $\mathrm{Ca}^{++}$-dependent regulatory pathways.

In many instances, cytosolic $\mathrm{Ca}^{++}$and CAMP may be considered as two components of a single interlocking regulatory systom (for a review, see Cheung and Storm, 1982 and Rasmussen, 1982). The simplest scheme that is in keeping with this viewpoint and with the data presented in this report is shown in Figure 7. This scheme depicts a multistep negative feedback loop by which electrical activity regulates the density of TTX-sensitive $\mathrm{Na}^{+}$channels. According to this proposal, $\mathrm{Ca}^{++}$, which is released from the sarcoplasmic reticulum in response to electrical activity, binds to and activates calmodulin. The activated calmodulin in turn may alter the density of sodium channels in one of two ways. It may act directly to reduce sodium channel synthesis and/or processing. Alternatively, it may enhance the catalytic rate of CAMP phosphodiesterase. The reduced levels of CAMP are then the proximate cause of reduced TTXsensitive channel density. The data presented in this report clearly support the steps indicated by the solid arrows. We have not, however, presented evidence to support the links between activated calmodulin, phosphodiesterase, and intracellular CAMP as indicated by the dashed arrows.

The level of CAMP is generally thought to be regulated by interaction of cell surface hormone receptors with adenylate cyclase. However, the level of cAMP may also be regulated through alterations of the rate of hydrolysis by cyclic nucleotide phosphodiesterases (Meeker and Harden, 1982; Miot et al., 1983). There are several types of phosphodiesterases and more than one type has been

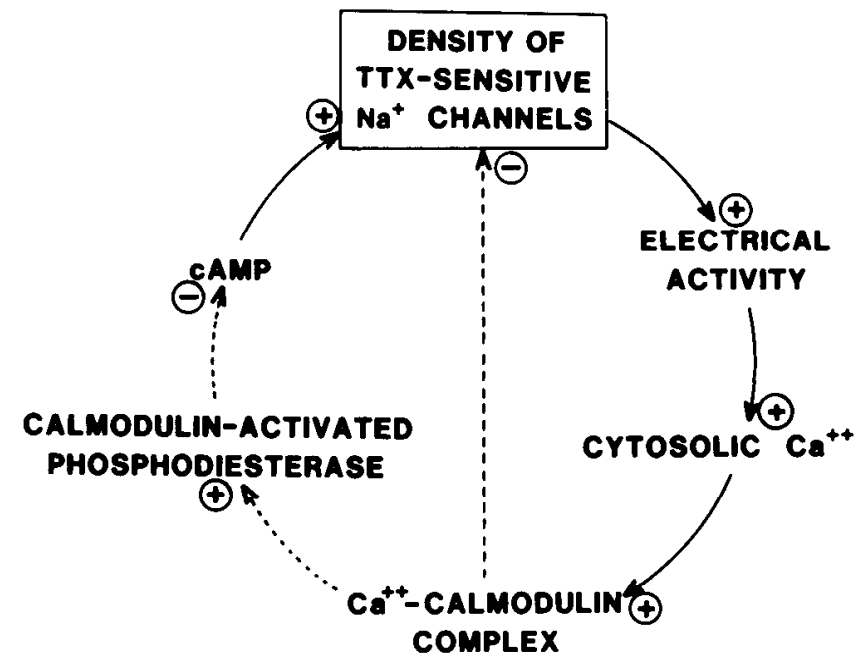

Figure 7. Schematic diagram showing possible links between the $\mathrm{Ca}^{++}$. dependent and CAMP-dependent regulatory systems controlling the density of TTX-sensitive $\mathrm{Na}^{+}$channels. The dashed arrow indicates that no experimental data have been presented to directly substantiate this link (see the text for complete discussion).

identified in most tissues studied (Moon and Christianson, 1971; Thompson et al., 1979). One of these types is greatly stimulated by the $\mathrm{Ca}^{++}$-calmodulin complex and thus provides a link between the $\mathrm{Ca}^{++}$-dependent and cAMP-dependent regulatory systems (for review, see Cheung and Storm, 1982). Since electrical activity in muscle must raise the time-averaged concentration of cytosolic $\mathrm{Ca}^{++}$, the presence of a $\mathrm{Ca}^{++}$-calmodulin-stimulated phosphodiesterase would be expected to cause a decrease in cAMP levels in response to electrical activity. Indeed, in frog sartorius muscle, the level of CAMP is inversely proportional to the tension developed during muscle tetanus (Fano et al., 1981). However, Merican et al. (1983) did not find such a relationship between twitch frequency and CAMP level in adult cat muscle. There may be substantial variations among different muscle preparations with regard to the amounts of calmodulin-activated phosphodiesterase. Thus, further experiments are necessay to determine the relationship between levels of cytosolic $\mathrm{Ca}^{++}$. $\mathrm{Ca}^{++} /$calmodulin-activated phosphodiesterase, and CAMP in cultured rat muscle cells.

Significance of the regulation of sodium channel number by second messengers. Regardless of which is the correct mechanism of action, the actions of CAMP, cytosolic $\mathrm{Ca}^{++}$, and electrical activity on levels of functional TTX-sensitive sodium channels are important because they provide a mechanism by which electrical excitability may be regulated in a long-term fashion by intracellular second messengers. Comparison with other results suggests that second messengers may serve to coordinate the regulation of a number of proteins involved in neuromuscular transmission. For example, the density of acetylcholine receptors is also regulated by electrical activity (Shainberg and Burstein, 1976) and cytosolic $\mathrm{Ca}^{++}$levels (McManaman et al., 1982; Forrest et al., 1981). Treatment of muscle cells with A23187 (McManaman et al., 1982) or ryanodine (Pezzementi and Schmidt, 1981) has remarkably similar effects on acetylcholine receptors and $\Pi \mathrm{TX}$-sensitive $\mathrm{Na}^{+}$channels. Also, similar to results presented here for the TTX-sensitive $\mathrm{Na}^{+}$channel, electrical activity (Brookes and Hall, 1975) and cytosolic $\mathrm{Ca}^{++}$(Pezzementi and Schmidt, 1981) regulate the density of acetylcholine receptors without affecting their turnover rate. Finally, as reported here for the TTX-sensitive $\mathrm{Na}^{+}$channel, the density of acetylcholine receptors is regulated by CAMP but not by CGMP (McManaman et al., 1982). It seems unlikely that thesc similaritics are coincidental. Rather, they are likely to reflect an important underlying mechanism by which the levels of acetylcholine receptors and TTX-sensitive $\mathrm{Na}^{+}$channels are coordinately regulated. This regulation represents a potentially 
important process in homeostatic maintenance of an appropriate level of electrical and chemical excitability of muscle cells.

\section{References}

Appleman, M. M., W. J. Thompson, and T. R. Russell (1973) Cyclic nucleotide phosphodiesterases. Adv. Cyclic Nucleotide Res. 3: 65-98.

Bar-Sagi, D., and J. Prives. (1983) Tunicamycin inhibits the expression of surface $\mathrm{Na}^{+}$channels in cultured muscle cells. J. Cell. Physiol. 114. 7781.

Bianchi, C. P. (1963) Action on calcium movements in frog sartorius muscles by drugs producing rigor. J. Cell. Comp. Physiol. 61: 255-263.

Brockes, J. P., and Z. W. Hall (1975) Synthesis of acetylcholine receptor by denervated rat diaphragm muscle. Proc. Natl. Acad. Sci. USA 72: 13681371

Catterall, W. A. (1980a) Neurotoxins that act on voltage-sensitive sodium channels in excitable membranes. Annu. Rev. Pharmacol. Toxicol. 20: 1543

Catterall, W. A. (1980b) Pharmacologic properties of voltage-sensitive sodium channels in chick muscle fibers developing in vitro. Dev. Biol. 78. 222230.

Catterall, W. A., C. S. Morrow, and R. P. Hartshorne. (1979) Neurotoxin binding to receptor sites associated with voltage-sensitive sodium channels in intact, lysed, and detergent solubilized brain membranes. J. Biol. Chem. 254: $11379-11387$.

Cheung, W. Y. (1980) Calmodulin plays a pivotal role in cellular regulation. Science 107: 19-27.

Cheung, W. Y., and D. R. Storm (1982) Calmodulin regulation of cyclic AMP metabolism. In Handbook of Experimental Pharmacology 58/1. J. A. Nathanson and J. W. Kebabian, eds., Berlin, Heidelberg, New York, SpringerVerlag.

Cohen, S. A., and R. L. Barchi (1981) Glycoprotein characteristics of the sodium channel saxitoxin-binding component from mammalian sarcolemma. Biochim. Biophys. Acta 645: 253-261.

Costa, M. R. C., and W. A. Catterall (1984) Cyclic AMP-dependent phosphorylation of the $\alpha$ subunit of the sodium in synaptic nerve ending particles. J. Biol. Chem. 259: 7918-7921.

Elbein, A. D. (1981) The tunicamycins-useful tools for studies on glycoproteirrs. Trends Biochem. Sci. 6: 219-221.

Fairhurst, A. S., and G. Hasselbach (1970) Calcium efflux from a heavy sarcotubular fraction. Eur. J. Biochem. 13: 504-509.

Fano, G., D. T. Giovanella, B. P. Giovanni, M. U. Blanca, and O. Aldo (1981) Effect of theophylline and imidazole on cyclic AMP and cyclic GMP levels in active sartorius muscle of Rana esculenta. Pharmacol. Res. Commun. 13: $451-459$.

Forrest, J. W., R. G. Mills, J. J. Bray, and J. I. Hubbard (1981) Calciumdependent regulation of the membrane potential and extrajunctional acetylcholine receptors of rat skeletal muscle. Neuroscience 6: 1741-1749.

Frelin, C., A. Lombet, P. Vigne, G. Romey, and M. Lazdunski (1981) The appearance of voltage-sensitive $\mathrm{Na}^{+}$channels during the in vitro differentiation of embryonic chick skeletal muscle cells. J. Biol. Chem. 254: 3600 3607.

Gietzen, K., A. Wuitrich, and H. Bader (1981) R24571: A new powerful inhibitor of red blood cell $\mathrm{Ca}^{++}$-transport ATPase and of calmodulin regulated functions. Biochem. Biophys. Res. Commun. 101: 418-425.

Hainaut, K., and D. E. Desmedt (1979) Dantrolene and A23187 ionophore specific action on calcium channels revealed by the aequorin method. Biochem. Pharmacol. 28: 957-964.

Hajdu. S. (1969) Mechanism of the Woodworth staircase phenomenon in heart and skeletal muscle. Am. J. Physiol. 216: 206-214.

Hartshorne, R. P., and W. A. Catterall (1981) Purification of the saxitoxin receptor of the sodium channel from rat brain. Proc. Natl. Acad. Sci. U. S. A. $78: 4620-4624$.

Jenden, D. J., and A. S. Fairhurst (1969) The pharmacology of ryanodine. Pharmacol. Rev. 21: 1-25.

Kidokoro, Y., S. Heinemann, D. Schubert, B. L. Brandt, and F. G. Klier (1975) Synapse formation and neurotrophic effects on muscle cell lines. Cold Spring Harbor Symp. Quant. Biol. 40: 373-388.

Klee, C. B., T. H. Crouch, and P. G. Richman (1980) Calmodulin. Annu. Rev. Biochem. 49: 489-515

Krebs, E. G., and J. A. Beavo (1979) Phosphorylation-dephosphorylation of enzymes. Annu. Rev. Biochem. 48: 923-960.

Lawrence, J. C., and W. A. Catterall (1981) Tetrodotoxin-insensitive sodium channels: Binding of polypeptide neurotoxins in primary cultures of rat muscle cells. J. Biol. Chem. 256: 6223-6229
Levin, R. M., and Weiss, B. (1977) Binding of trifluoperazine to the calciumdependent activator of cyclic nucleotide phosphodiesterase. Mol. Phar macol. 13: 690-697.

Lowry, O. H., N. J. Rosebrough, A. L. Farr, and R. J. Randall (1951) Protein measurement with the Folin phenol reagent. J. Biol. Chem. 192: 265-275.

McManaman, J. L., J. C. Blosser, and S. H. Appel (1982) Inhibitors of membrane depolarization regulate acetylcholine receptor synthesis by a calcium-dependent, cyclic nucleotide-independent mechanism. Biochem. Biophys. Acta 720: 28-35.

Meeker, R. B., and T. K. Harden (1982) Muscarinic cholinergic receptormediated activation of phosphodiesterase. Mol. Pharmacol. 22: 310-319.

Merican, Z., M. W. Nott, and M. Sunbhanich (1983) Effects of increasing the frequency of twitches and of isoprenaline on maximal twitches and cyclic AMP levels in slow- and fast-contracting cat skeletal muscles. Br. J. Pharmacol. 80: 303-308.

Mint, F., J. E. Dumont, and C. Erneux (1983) The involvement of a calmodulin dependent phosphodiesterase in the negative control of carbamylcholine on cyclic AMP levels in dog thyroid slices. FEBS Lett. 151: 273-276.

Moon, E., and R. O. Christiansen (1971) Adenosine $3^{\prime} 5^{\prime}$-monophosphate phosphodiesterase. Science 173: 540-541.

Narahashi, T. (1974) Chemicals as tools in the study of excitable membranes. Physiol. Rev. 54: 813-889.

Olson, E. N., L. Glaser, J. P. Merlie, and J. Lindstrom (1984) Expression of acetylcholine receptor $\alpha$-subunit mRNA during differentiation of the $\mathrm{BC}_{3} \mathrm{H} 1$ muscle cell line. J. Biol. Chem. 259: 3330-3336.

Pappone P. A. (1980) Voltage clamp experiments in normal and denervated mammalian skeletal muscle fibers. J. Physiol. (Lond.) 306: 377-340.

Pezzementi, L., and J. Schmidt (1981) Ryanodine alters the rate of acetylcholine receptor synthesis in chick skeletal muscle cells. J. Biol. Chem. 264: 1265I-12654.

Rasmussen, H. (1982) Interactions between the cAMP and $\mathrm{Ca}^{++}$messenger systems. Horiz. Biochem. Biophys. 6: 175-197.

Redfern, P., and S. Thesleff (1971) Action potential generation in denervated rat skeletal muscle. II. The action of tetrodotoxin. Acta Physiol. Scand. 82. $70-78$.

Rhoden, V. A., and S. M. Goldin (1979) The binding of saxitoxin to axolemma of mammalian brain. J. Biol. Chem. 254: 11199-11201.

Ritchie, J. M. R. B. Rogart, and G. R. Strichartz (1976) A new method for labelling saxitoxin and its binding to non-myelinated fibers of the rabbit vagus, lobster walking leg, and garfish olfactory nerves. J. Physiol. (Lond.) 261: 477-494.

Ritchie, J. M., and R. B. Rogart (1977a) The binding of saxitoxin and tetrodotoxin to excitable tissue. Rev. Physiol. Biochem. Pharmacol. 79: 151

Seamon, K. B., and J. W. Daly (1981) Forskolin: a unique activator of CAMP. generating systems. J. Cyclic Nucleotide Res. 7: 201-224.

Shainberg, A., and M. Burstein (1976) Decrease of acetyicholine receptor synthesis in muscle cultures by electrical stimulation. Nature 264: 368369

Sherman, S. J., J. C. Lawrence, D. J. Messner, K. Jacoby, and W. A. Catterall (1983) Tetrodotoxin-sensitive sodium channels in rat muscle cells developing in vitro. J. Biol. Chem. 258: 2488-2495.

Sherman, S. J., and W. A. Catterall (1984) Electrical activity and cytosolic calcium regulate levels of tetrodotoxin-sensitive sodium channels in cultured rat muscle cells. Proc. Natl. Acad. Sci. U. S. A. 81: 262-266.

Sieghart, W., J. Forn, and P. Greengard (1979) $\mathrm{Ca}^{2+}$ and cyclic AMP regulate phosphorylation of same two membrane-associated proteins specific to nerve tissue. Proc. Natl. Acad. Sci. U. S. A. 76: 2475-2479.

Spector, I., and J. Prives (1977) Development of electrophysiological and biochemical membrane properties during differentiation of embryonic skeletal muscle in culture. Proc. Natl. Acad. Sci. U. S. A. 74: 5166-5170.

Struck, D. K., and W. J. Lennarz (1980) The Biochemistry of Glycoproteins and Proteoglycans, Lennarz, W. J., ed., pp. 35-83, Plenum Publishing Corp., New York.

Thompson, W. J., W. L. Terrasaki, P. M. Epstein, and S. J. Strada (1979) Assay of cyclic nucleotide phosphodiesterase and resolution of multiple molecular forms of the enzyme. Adv. Cyclic Nucleotide Res. 10: 69-92.

Van Belle, H. (1981) R24571: A potent inhibitor of calmodulin-activated enzymes. Cell Calcium 2: 483-494.

Waechter, C. J., J. W. Schmidt, and W. A. Catterall (1983) Glycosylation is required for maintenance of functional sodium channels in neuroblastoma cells. J. Biol Chem. 258: 5117-5123

Weiss, B., and R. M. Levin (1978) Mechanism for selectively inhibiting the activation of cyclic nucleotide phosphodiesterase and adenylate cyclase by antipsychotic agents. Adv. Cyclic Nucleotide Res. 9: 285-304. 